\title{
Atmospheric Gravity Waves and Effects in the Upper Atmosphere Associated with Tsunamis
}

\author{
Michael P. Hickey \\ Embry-Riddle Aeronautical University \\ USA
}

\section{Introduction}

Tsunamis propagate at the surface of the deep ocean horizontal phase speeds of approximately $200 \mathrm{~m} / \mathrm{s}$, which is about two-thirds of the lower atmospheric sound speed. They have large horizontal wavelengths that are typically of a few hundred kilometers, and they remain coherent over large propagation distances. They also have large horizontal extents (sometimes a few thousand kilometers) parallel to their wave fronts. They can traverse great distances over a span of several hours, so that large areas of the oceanatmosphere interface are impacted. Typical dominant wave periods associated with tsunamis are a few tens of minutes. In the deep ocean their amplitudes are usually quite small with surface displacements being only a few centimeters, but occasional large events can have amplitudes of a few tens of $\mathrm{cm}$.

The speeds, wavelengths and periods of tsunamis lie within the range of those of atmospheric gravity waves. These are vertically transverse waves with motions of air parcels mainly influenced by gravity and buoyancy. The vertical displacement of the water acts like a moving corrugation at the base of the atmosphere and so very effectively generates atmospheric gravity waves. In general a spectrum of waves will be produced by a tsunami. Most of the power in the spectrum resides in internal gravity waves, with acoustic waves and evanescent waves being less efficiently generated. Internal waves can transport energy and momentum vertically through the atmosphere. Due to the decrease of mean atmospheric density with increasing altitude, the amplitude of these waves increases as they propagate upward in order to conserve wave energy. At sufficiently high altitudes molecular viscosity and thermal conductivity damp the waves, and their amplitudes then decrease with increasing altitude. Because the waves have high phase speeds (commensurate with the tsunami speed), they are deep waves with vertical wavelengths of $\sim 100 \mathrm{~km}$. This allows them to reach the middle thermosphere $(\sim 250 \mathrm{~km}$ altitude) before the molecular dissipation becomes severe.

Atmospheric winds also influence the upward propagation of atmospheric gravity waves. Because the winds vary with height the waves may be propagating with the wind at some heights and against the wind at other heights. In the former case the vertical wavelengths are shortened, which increases the velocity shears and thereby increases the viscous damping rate. In the latter case the vertical wavelengths are increased, which decreases the velocity shears and decreases the viscous damping rate.

At these heights the tsunami-driven atmospheric gravity waves have large amplitudes so that their interaction with the ionosphere is likely to produce detectable traveling 
ionospheric disturbances (TIDs). These TIDs have been observed in GPS measurements of total electron content and have exhibited a strong correlation with individual tsunami events. Modeling studies have helped the interpretation of such observations. The interaction between the neutral particles and the ions also leads to a further loss of wave energy through ion drag, but viscous effects dominate over ion drag for the typical gravity wave periods associated with tsunamis.

In addition to perturbations of the ionization, the chemistry of the thermosphere is also affected by atmospheric gravity waves. Chemiluminescent airglow emissions associated with neutral and ion chemistry are then affected. These emissions that emanate from a deep region centered at $\sim 250 \mathrm{~km}$ altitude can be observed from the ground and/or from space. Oblique viewing allows the tsunami-driven disturbances in the thermosphere to be seen from considerable horizontal distances.

Internal atmospheric gravity waves can also transport energy and momentum over considerable vertical distances. The importance of this is due to the considerable decreases of atmospheric density with increasing altitude. In the tenuous upper atmosphere the deposition of small quantities of wave momentum can have a profound effect. Simulations suggest that for large tsunami events the dissipating gravity waves can accelerate the middle thermosphere by $\sim 100 \mathrm{~m} / \mathrm{s}$ within a few hours. These modeling predictions are yet to be confirmed by observations.

In this article observations and modeling of tsunami-driven atmospheric gravity waves are reviewed. Particular emphasis is given to the theory of atmospheric gravity waves, their vertical propagation, and their interaction with the ionosphere and thermospheric chemistry. The ability to measure a disturbance at a large distance from the tsunami offers a means of early detection to augment other early warning measurements. The utility of modeling and simulation in the interpretation of such tsunami-driven disturbances in the thermosphere is demonstrated.

\section{Atmospheric acoustic-gravity waves}

Around the dawn of the twentieth century with the advent of radio wave communications came the subsequent discovery of the ionosphere. New research was initiated related to ionospheric physics and chemistry and many new discoveries followed. One of these was the existence of traveling ionospheric disturbances (TIDs), which were ionospheric irregularities propagating rapidly in the horizontal direction with speeds of many tens to hundreds of $\mathrm{m} / \mathrm{s}$, and often with large horizontal wavelengths of 100s of km (Munro, 1948). Martyn (1950) was the first to explain the TIDs in terms of internal atmospheric gravity waves, and Hines (1960) finally produced a correct and unambiguous description of the phenomenon in terms of these waves.

Atmospheric gravity waves are fluctuations of the neutral atmosphere, usually triggered by events that cause a lifting of localized regions of the atmosphere. In the lower atmosphere sources of gravity waves include severe weather systems (Georges, 1968), and winds blowing over mountains (Scorer, 1949). A more complete discussion of these and other sources is given by Fritts and Alexander (2003). Gravity waves are the low frequency component of the more general class of acoustic-gravity waves. The acoustic waves, of higher frequencies than gravity waves, are primarily driven by events that produce a rapid compression of a region of the atmosphere. We remark that compressional effects are also important for high frequency gravity waves. At very high altitudes the oscillatory motion of 
air particles associated with gravity waves causes the ionospheric ions (and electrons) to oscillate due to neutral-ion collisions. The ion-electron motions are constrained by the geomagnetic field, chemistry, and electric fields.

The initial theory of acoustic-gravity waves of Hines (1960) was based on an idealized atmosphere (windless, isothermal, adiabatic wave motions). This important study showed that internal atmospheric gravity wave amplitudes will grow exponentially with increasing height as the waves propagate upward in order to conserve wave energy. If mean pressure and density decrease exponentially as $\mathrm{e}^{-\mathrm{z} / \mathrm{H}}$ (where $H$ is the atmospheric scale height), then wave amplitudes grow as $\mathrm{e}^{\mathrm{z} / 2 \mathrm{H}}$. Due to the fact that the mean atmospheric density decreases by a factor of $\sim 10^{6}$ between sea level and the lower thermosphere (near $100 \mathrm{~km}$ altitude), wave amplitudes will increase by a factor of $\sim 10^{3}$ during the upward propagation of the waves over this region. A dispersion relation was derived relating the vertical wavelength $\left(\lambda_{z}=2 \pi / m\right)$ to the horizontal wavelength $\left(\lambda_{x}=2 \pi / k\right)$ and wave period $(T=2 \pi / \omega)$

$$
m^{2}=k^{2}\left(\frac{N^{2}}{\omega^{2}}-1\right)-\frac{\left(\omega_{a}^{2}-\omega^{2}\right)}{C^{2}}
$$

Here, $\omega$ is the wave frequency, $m$ is the vertical wavenumber, and $k$ is the horizontal wavenumber. Also, $C(\sqrt{\gamma g H})$ is the sound speed, $N$ is the Brunt-Väisälä frequency (for an isothermal atmosphere $\left.N^{2}=(\gamma-1) g^{2} / C^{2}\right)$, and $\omega_{a}(=\gamma g / 2 C)$ is the acoustic cut-off frequency. Also, $\gamma$ is the ratio of specific heats and $g$ is the gravitational acceleration. Inspection of Equation (1) reveals that internal waves (those with real $m$ ) exist for either $\omega<N$ (gravity waves) or for $\omega>\omega_{a}$ (acoustic waves). For intermediate wave frequencies $N<\omega<\omega_{a}$ only evanescent waves exist. Internal waves $\left(m^{2}>0\right)$ can transport energy and momentum vertically through the fluid in which they propagate, but evanescent waves $\left(m^{2}<0\right)$, of which surface waves are a subset, cannot. Typically, gravity waves have periods ranging from $\sim 10 \mathrm{~min}$ to a few hours, and horizontal wavelengths ranging from a few tens of $\mathrm{km}$ to several hundreds of $\mathrm{km}$ (occasionally even larger). They propagate with phase speeds of tens to hundreds of $\mathrm{m} / \mathrm{s}$, and are subsonic. Because of this, the slower gravity waves tend to have lower atmospheric sources (where the sound speed is lower), while fast gravity waves have high altitude sources where the sound speed is high. Gravity waves are vertically-transverse waves primarily influenced by the competing effects of gravity and buoyancy.

To help better understand the propagation of gravity waves we next examine the atmospheric mean state. Figure 1a shows altitude profiles of the mean temperature $(T)$ obtained from the MSIS-90 model (Hedin, 1991), and the derived Brunt-Väisälä period $\left(\tau_{B}\right)$ and the sound speed $C$. The conditions are appropriate for the equator at times of low solar and geomagnetic activity (see Hickey et al., 2009). The temperature increases rapidly in the lower thermosphere, and asymptotes to a value of $\sim 753 \mathrm{~K}$ in the upper thermosphere. In the thermosphere $\tau_{B}$ increases rapidly with increasing height and asymptotes to a value of $\sim 12$ min at high altitudes. Hence gravity waves having periods exceeding $\sim 12 \mathrm{~min}$ will be internal at all heights ( $\omega<N$ everywhere). The altitude variation of $\tau_{B}$ suggests that waves with periods satisfying $4 \mathrm{~min} \leq \mathrm{T} \leq 12 \mathrm{~min}$ will be evanescent over some altitude range and 
so would have diminished amplitudes at high altitudes. Hence, gravity waves with periods exceeding $\sim 12 \mathrm{~min}$ should dominate the F-region (near $300 \mathrm{~km}$ altitude) response to an upward propagating gravity wave disturbance. The sound speed profile suggests that gravity waves of lower atmosphere origin will have phase speeds of less than about $300 \mathrm{~m} / \mathrm{s}$.

The corresponding mean winds used in our model, obtained with the HWM93 model (Hedin et al., 1996), are shown in Figure 1b. The meridional winds remain relatively small at most altitudes, with a maximum value of $\sim 30 \mathrm{~m} / \mathrm{s}$ (northward) near $250 \mathrm{~km}$ altitude. The zonal winds are much larger in the thermosphere, and approach $70 \mathrm{~m} / \mathrm{s}$ (eastward) at high altitudes. Because the tsunami-generated gravity waves are fast $(\sim 200 \mathrm{~m} / \mathrm{s})$, we expect them to be relatively unaffected by the meridional winds. On the other hand, the zonal winds are expected to influence the gravity waves.

\section{Tsunami-related upper atmosphere observations}

Hines (1972) first postulated that tsunamis may be capable of producing atmospheric gravity waves that could subsequently propagate to high altitudes. Later, Peltier and Hines (1976) demonstrated the plausibility of this idea using a simple model of a gravity wave disturbance. The subject of tsunami-generated gravity waves remained relatively unexplored until the observations of Artru et al. (2005). They used Global Positioning System (GPS) measurements of total electron content (TEC) following the earthquake of Peru on June 23, 2001, and showed that the observed ionospheric disturbance had similar characteristics to the expected tsunami-generated gravity wave. In particular, they derived a horizontal propagation velocity of $\sim 150 \mathrm{~m} / \mathrm{s}$ in a direction consistent with the source location. Ionospheric observations showing evidence of gravity waves following the December 262004 Sumatra tsunami were reported by Liu et al. (2006a, b) and by DasGupta et al. (2006). Lee et al. (2008) observed large ionospheric variations with accompanying spread F over Arecibo on the evening of December 262004 . They postulated that tsunamigenic gravity waves associated with the Sumatra event were responsible for the observations.

\section{Modeling gravity wave propagation}

\subsection{Previous modeling}

Artru et al. (2005) used the basic theory developed by Hines (1960) to model gravity wave propagation and to provide a match to their observations. Ionospheric perturbations were not specifically modeled. However, by deriving the group velocities for the disturbances they were able to obtain good agreement between modeled and observed propagation times for the disturbances.

Occhipinti et al. (2006) performed time-dependent modeling of the December 26th 2004 Sumatra tsunamigenic gravity waves assuming that the atmospheric wave motions were inviscid and adiabatic. The ocean sea surface displacement was defined using a model of Hébert et al. (2007). A nonlinear ionospheric perturbation model was also included in order to be able to simulate the observed TEC observations. They found that the ionospheric response depended sensitively on the magnetic latitude (as described in the earlier work of Hooke, 1968). The relative TEC perturbation amplitudes were about $10 \%$, which was noted to be in agreement with the observations of Liu et al. (2006b). Their results were also found to be largely insensitive to the effects of ion chemistry and diffusion. Occhipinti et al. (2008) continued from their previous work with a strong focus on the latitudinal variation of the 


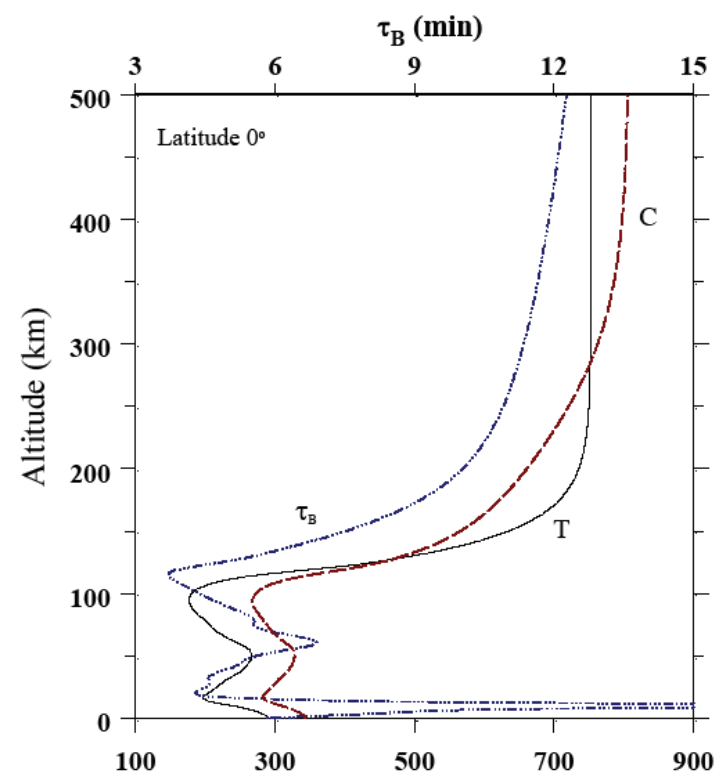

Temperature $(\mathrm{K})$ and Sound Speed $(\mathrm{m} / \mathrm{s})$

Fig. 1a. Mean temperature $(T$, in $K)$, sound speed $(C$, in $\mathrm{m} / \mathrm{s})$ and Brunt-Väisälä period $\left(\tau_{B}\right.$ ， in min). After Hickey et al. (2009)

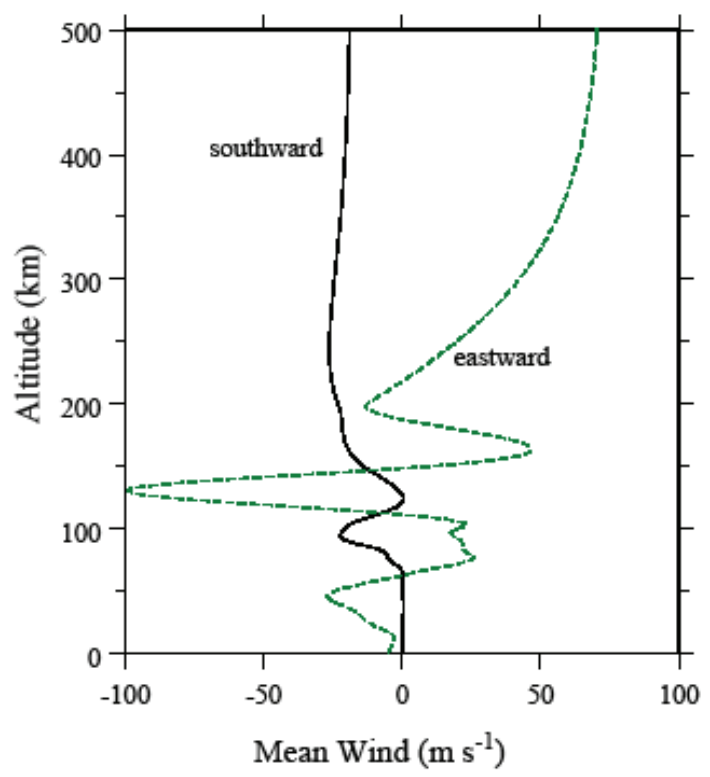

Fig. 1b. Mean southward and eastward winds (m/s). After Hickey et al. (2009) 
ionospheric response to a tsunamigenic gravity wave. A clear anisotropic response was noted in their derived TEC perturbations. Note that their model used the Boussinesq approximation which applies to low frequency gravity waves for which the perturbations can be assumed to be incompressible; hence the model is essentially the same as that of Occhipinti et al. (2006).

\subsection{Full-wave model description}

The full-wave model, described below, has been previously used to model acoustic wave (Hickey et al., 2001; Schubert et al., 2005; Walterscheid and Hickey, 2005) and gravity wave (Hickey et al., 1997; Walterscheid and Hickey, 2001) propagation in Earth's atmosphere. A Cartesian coordinate system is used with $x, y$ and $z$ directed southward, eastward, and upward, respectively. The unperturbed mean state atmosphere is assumed to vary only in the vertical direction and is specified using the MSIS model (Hedin, 1991). For the simulations discussed later the lower boundary of the model is at the ground $(z=0)$ and the upper boundary is at $z=600 \mathrm{~km}$.

The model solves the Navier-Stokes equations for steady, linear waves propagating in an atmosphere that is horizontally homogeneous and stratified vertically. The mean, undisturbed state is non-isothermal, and mean winds are a function of height. The model includes the eddy and molecular diffusion of heat and momentum, ion drag, Rayleigh friction and Newtonian cooling, and the Coriolis force. The momentum equation is

$$
\rho \frac{D \vec{v}}{D t}+\underline{\nabla} p-\rho \vec{g}+2 \rho \vec{\Omega}_{E} \times \vec{v}+\underline{\nabla} \cdot \underline{\sigma}-\underline{\nabla} \cdot\left(\rho \eta_{e} \underline{\nabla} \vec{v}\right)-\rho v_{n i}\left(\vec{v}_{i}-\vec{v}\right)+\rho K_{R} \vec{v}=0
$$

In this equation $\rho$ is mass density, $\vec{v}$ is velocity, $p$ is pressure, $\vec{g}$ is the gravitational acceleration, $\vec{\Omega}_{E}$ is the Earth's angular frequency, $\sigma$ is the viscous stress tensor, $\eta_{e}$ is the eddy diffusivity, $v_{n i}$ is the neutral-ion collision frequency, $\vec{v}_{i}$ is the ion velocity, and $K_{R}$ is the Rayleigh friction coefficient. Also, $D / D t=\partial / \partial t+\vec{v} \cdot \underline{\nabla}$ is the substantial derivative, where $t$ is time. The viscous stress tensor is defined as

$$
\sigma_{i j}=-\mu_{m}\left(\frac{\partial v_{i}}{\partial x_{j}}+\frac{\partial v_{j}}{\partial x_{i}}-\frac{2}{3} \delta_{i j} \underline{\nabla} \cdot \vec{v}\right)
$$

where $\mu_{m}$ is the dynamic viscosity and $\delta_{i j}$ is the Kroneka delta.

The energy equation is

$$
\rho c_{v} \frac{D T}{D t}+p \underline{\nabla} \cdot \vec{v}+\underline{\sigma}: \underline{\nabla} \vec{v}-\underline{\nabla} \cdot\left(\lambda_{m} \underline{\nabla} T\right)-\frac{c_{p} T}{\theta} \underline{\nabla} \cdot\left(\rho \kappa_{e} \underline{\nabla} \theta\right)-\rho v_{n i}\left(\vec{v}_{i}-\vec{v}\right)^{2}+\rho c_{v} K_{N} T=0
$$

Here $T$ is temperature, $\lambda_{m}$ is the coefficient of thermal conductivity, $c_{p}$ and $c_{v}$ are the specific heats at constant pressure and constant volume, respectively, $\kappa_{e}$ is the eddy diffusivity of heat, and $K_{N}$ is the Newtonian cooling coefficient. In these studies we set $K_{N}$ equal to $K_{R}$. At the upper boundary they serve as a sponge layer and are set equal to the wave frequency; at lower altitudes they decrease exponentially away from the upper boundary with a characteristic scale height of $50 \mathrm{~km}\left(K_{N}=\omega \exp [(z-600 \mathrm{~km}) / 50 \mathrm{~km}]\right.$. The 
potential temperature is defined as $\theta=T\left(p_{00} / p\right)^{R / c_{p}}$, where $\mathrm{R}$ is the gas constant and $p_{00}$ is a reference pressure (taken to be the sea-level value).

The continuity equation is

$$
\frac{D \rho}{D t}+\rho \underline{\nabla} \cdot \vec{v}=0
$$

The linearized equation of state for an ideal gas $\left(p^{\prime} / \bar{p}=\rho^{\prime} / \bar{\rho}+T^{\prime} / \bar{T}\right)$ completes the set. Here primes denote perturbation values and the over-bar signifies the mean state.

The solution procedure involves first linearizing Eqs. (2) through (5), and then eliminating density perturbations $\left(\rho^{\prime}\right)$ using the linearized ideal gas equation of state. Next, plane wave solutions of the form expi $(\omega t-k x-l y)$ are assumed, where $\omega$ is the wave frequency, $t$ is time, and $k$ and $l$ are the wavenumbers in the $x$ and $y$ directions, respectively. This allows the terms involving time and horizontal derivatives to be replaced by algebraic terms. The remaining system of equations is essentially a set of coupled second order differential equations in the vertical coordinate, $z$. A complete listing of these equations is provided in the appendix of Schubert et al. (2003) and by Hickey et al. (2004). These equations are then written in their finite-difference form and solved using a method described by Bruce et al. (1953), as modified by Lindzen and Kuo (1969). At the upper boundary $(z=600 \mathrm{~km})$ a radiation condition is assumed with solutions provided using a dispersion equation described by Hickey and Cole [1987]. The lower boundary (ground) condition allows the vertical velocity to be specified. The equations are solved on a high resolution grid with the vertical spacing chosen to be typically several meters. The input required for the model is the altitude profile of the mean state (temperature, density, molecular weight, and horizontal winds), the wave amplitude, period, horizontal wavelength and direction of propagation. The model produces altitude profiles of amplitude and phase for the perturbations (three velocity components, temperature and pressure). From these other quantities of interest can be calculated, such as momentum, sensible heat and energy fluxes and their divergence.

\subsection{Spectral full-wave model}

The approach of Peltier and Hines (1976) is used to model the propagation of a tsunamigenerated gravity wave disturbance. The following description is also provided in Hickey et al. (2009). The initial $(t=0)$ displacement $Z$ at the sea surface $(z=0)$ is prescribed by

$$
Z(x, z=0, t=0)=A\left\{A i(-x+1) \frac{x}{2} \exp [-(x-2) / 2]\right\}
$$

where $A i$ is the Airy function, and $\mathrm{x}$ is the horizontal position in units of $100 \mathrm{~km}$. The amplitude of the forcing is $A$ (in meters). The Fourier transform of (6) provides the wavenumber $(k)$ spectrum of the forcing

$$
\hat{Z}(k, 0,0)=\frac{1}{2 \pi} \int_{-\infty}^{\infty} Z(x, 0,0) e^{i k x} d x
$$

Our simulations are based on long wavelength water waves propagating on the ocean surface. They are nondispersive and propagate with the shallow water phase speed 
$c=\sqrt{g h}$, where $g$ is the gravitational acceleration and $h$ is the ocean depth (Lighthill, 1978). The tsunami is taken to propagate in the negative $x$-direction (but this is later altered to accommodate propagation in any arbitrary direction) in an ocean of depth $4 \mathrm{~km}$. Hence $c=-200 \mathrm{~m} / \mathrm{s}$, whence $\omega=-200 k$. The vertical velocity spectrum is then given by

$$
\hat{W}(k, 0,0)=i \omega \hat{Z}(k, 0,0)=-i 200 k \hat{Z}(k, 0,0)
$$

We use a discrete Fourier transform to evaluate the spectrum of the surface displacement $\hat{Z}$ and the vertical velocity spectrum $\hat{W}$. Figures $1 \mathrm{a}$ and $1 \mathrm{~b}$ show the surface displacement $(Z)$ and the vertical velocity spectrum $(\hat{W})$.

Occhipinti et al. (2006) reported sea surface displacements measured by Jason- 1 and TopexPoseidon that were characterized by a dominant horizontal scale size of $400 \mathrm{~km}$ and an amplitude of $\sim 0.5 \mathrm{~m}$. Wilson (2005) reported similar values $(\sim 500 \mathrm{~km}$ and 0.3 to $0.6 \mathrm{~m}$, respectively). In Hickey et al. (2009) and here we adopt the former set of values. The amplitude of the surface displacement shown in Figure (2a) initially increases rapidly and diminishes after several cycles. The vertical velocity spectrum shown in Figure 2(b) is characterized by maxima at $\pm 400 \mathrm{~km}$, corresponding to a dominant period of $33 \mathrm{~min}$. This is in general agreement with the analysis of tide gauge measurements in and near the Indian Ocean that revealed periods ranging from 10 to $60 \mathrm{~min}$ and a dominant period of $40 \mathrm{~min}$ for the Sumatra tsunami event (Abe, 2006).

The full-wave model output is obtained for each discrete wave $(\omega-k)$ in the spectrum, with the vertical velocity at the lower boundary $(z=0)$ specified to be unity. If we denote this output by $\psi_{j}^{\prime}(\omega, k, z)$ (here the subscript $j$ denotes each of velocity, temperature or pressure), then the response to the forcing is given by

$$
\Psi_{j}^{\prime}(x+v t, z)=\frac{1}{2 \pi} \int_{-\infty}^{\infty} \hat{W}(k, 0,0) \psi_{j}^{\prime}(\omega, k, z) e^{-i k(x+v t)} d k
$$

Note that the product $\hat{W}(k, 0,0) \psi_{j}^{\prime}(\omega, k, z) \Delta k$ represents the response of a single wavenumber-dependent perturbation to the spectral forcing, where $\Delta k$ is the bandwidth. Because the Brunt-Väisälä period $\left(\tau_{B}\right)$ exceeds $\sim 4$ min everywhere (see Figure 1), waves of period $\sim 3$ to $\sim 4$ min will experience evanescence over much of the lower and middle atmosphere and so will be unable to propagate to the thermosphere. Waves of acoustic periods will not be efficiently generated by the tsunami, and moreover they will be evanescent because their phase speeds are less than the sound speed throughout the atmosphere. Hence we truncate the spectrum and include waves having periods of 3 min (wavelength $36 \mathrm{~km}$ ) and longer. Equation (9) was solved using 800 waves (400 positive $k$ and 400 negative $k$ ) for values of $\mathrm{x}$ ranging from $-1000 \mathrm{~km}$ to $+14400 \mathrm{~km}$ (and $\Delta k=4.36 \times 10^{-7} \mathrm{~m}^{-1}$ ).

\subsection{Ion-electron perturbation model}

The modeled electron-ion response to a linear gravity wave includes the effects of dynamics and chemistry. We use a solution procedure similar to that previously used to model the response of minor species and related airglow emissions in the mesospause region to gravity wave forcing (Walterscheid et al., 1987; Hickey, 1988). 


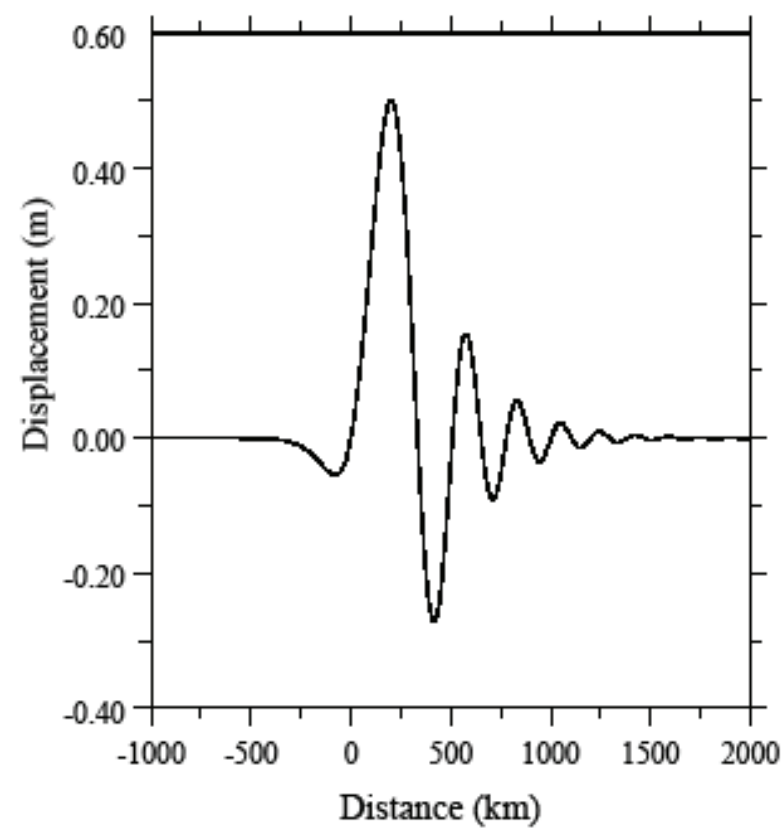

Fig. 2a. Surface displacement (after Hickey et al., 2009)

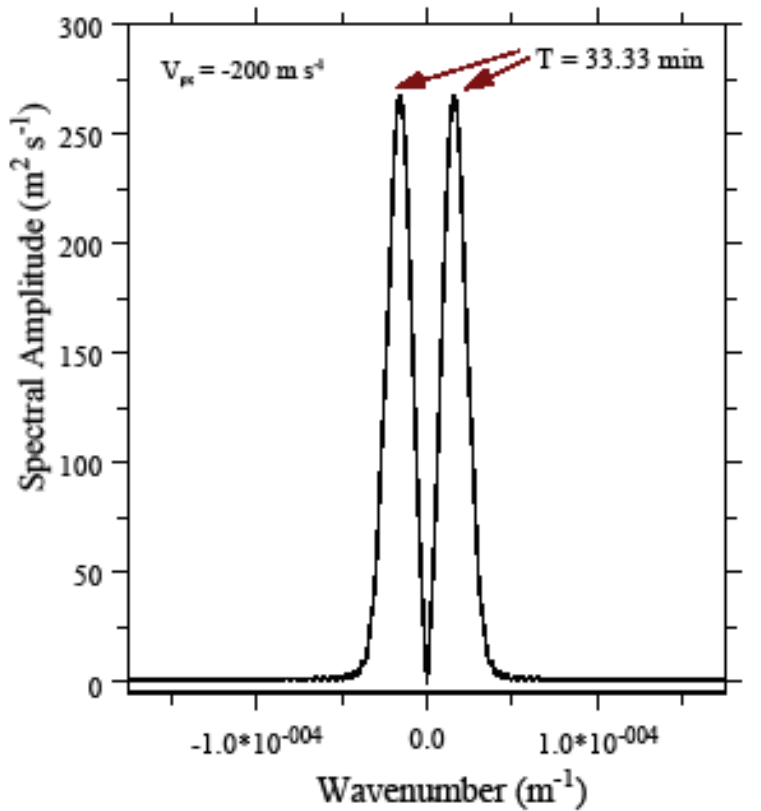

Fig. 2b. Vertical velocity spectrum at model lower boundary (after Hickey et al., 2009) 
The linearized perturbation ion continuity equations for each of the ion species $\mathrm{O}^{+}, \mathrm{O}_{2}{ }^{+}, \mathrm{N}_{2}{ }^{+}$ and $\mathrm{NO}^{+}\left(n_{j}\right)$ are

$$
i \omega n_{j}^{\prime}+w_{j}^{\prime} \frac{d \bar{n}_{j}}{d z}+\bar{n}_{j} \underline{\nabla} \cdot v_{j}^{\prime}=P_{j}^{\prime}-\bar{n}_{j} L_{j}^{\prime}-n_{j}^{\prime} \bar{L}_{j}
$$

Here, $P$ and $L$ are the chemical production and loss rates, respectively. They are calculated based on the set of chemical equations of Schunk and Sojka (1996), given in Appendix 1 (as in Hickey et al., 2010a). The electron density profile is based on a Chapman layer, with a maximum value of $10^{12} \mathrm{~m}^{-3}$ at $300 \mathrm{~km}$ altitude.

For the ion momentum equation we follow the approach of McLeod (1965) and neglect polarization electric fields, gravity and diffusion:

$$
\vec{v}_{i}=\left(\omega_{i}^{2}+v_{i n}^{2}\right)^{-1}\left\{v_{i n} \omega_{i} \vec{v} x \hat{B}+\omega_{i}^{2}(\vec{v} \cdot \hat{B}) \hat{B}+v_{i n}^{2} \vec{v}\right\}
$$

Here $\omega_{i}=q_{i} B / M_{i}$ is the ion gyrofrequency and $v_{i n}=2.6 \times 10^{-15}\left(n_{n}+n_{i}\right) A^{-1 / 2}($ Kelley, 1989) is the ion-neutral collision frequency, and where $q_{i}$ and $M_{i}$ are the charge and atomic or molecular weight, respectively of the ion, $B$ is the magnetic field strength in Gauss $\left(\mathrm{Wb} / \mathrm{m}^{2}\right)$, and $n_{\mathrm{n}}$ and $n_{\mathrm{i}}$ are the neutral and ion number density, respectively. Given the gravity wave perturbation velocity $\underline{v}^{\prime}$, Eq. (11) is used to determine $\underline{v}_{j}^{\prime}$ for each of the four ions. These ion velocities are then substituted in Eq. (10), and the system of four equations is inverted to yield the perturbation ion number densities. Other details of the calculations are provided in Hickey et al. (2009), and are not repeated here.

\section{Results}

\subsection{Electron fluctuations}

We begin by showing the results for the dominant wave in the spectrum. This wave has a period of $\sim 33 \mathrm{~min}$ and a horizontal wavelength of $400 \mathrm{~km}$. It is forced at the lower boundary of the full-wave model with a vertical velocity amplitude of $1.17 \times 10^{-4} \mathrm{~m} \mathrm{~s}^{-1}$. Mean winds, ion drag and Coriolis force are not included in this simulation, and so the propagation occurs isotropically in the horizontal direction.

The vertical velocity and temperature perturbation amplitudes are shown as a function of height in Figure 3a for two cases. In the first case the nominal viscosity and thermal conduction parameters are used, while in the second case these parameters are reduced by several orders of magnitude in order to mimic negligible dissipation (the adiabatic case). In the adiabatic case wave amplitudes increase by a factor of $10^{6}$ over the altitude range shown in order to conserve wave energy. In the case of nominal dissipation the waves eventually dissipate and achieve a maximum amplitude near $200 \mathrm{~km}$ altitude. The phase of the vertical velocity fluctuations is shown as a function of height in Figure $3 \mathrm{~b}$. This figure demonstrates that at high altitudes the dissipation causes an increase in the vertical wavelength of the waves. Up to about $250 \mathrm{~km}$ altitude the vertical wavelength is $\sim 100 \mathrm{~km}$ in both cases, but at high altitudes the vertical wavelength becomes very large in the non-adiabatic case.

The resulting $\mathrm{O}^{+}$velocity components for this wave are shown in Figure 4a. In this case we have included ion drag and the Coriolis force, and simulations are performed for the wave propagating either northward or eastward at the equator. The largest ion response occurs 


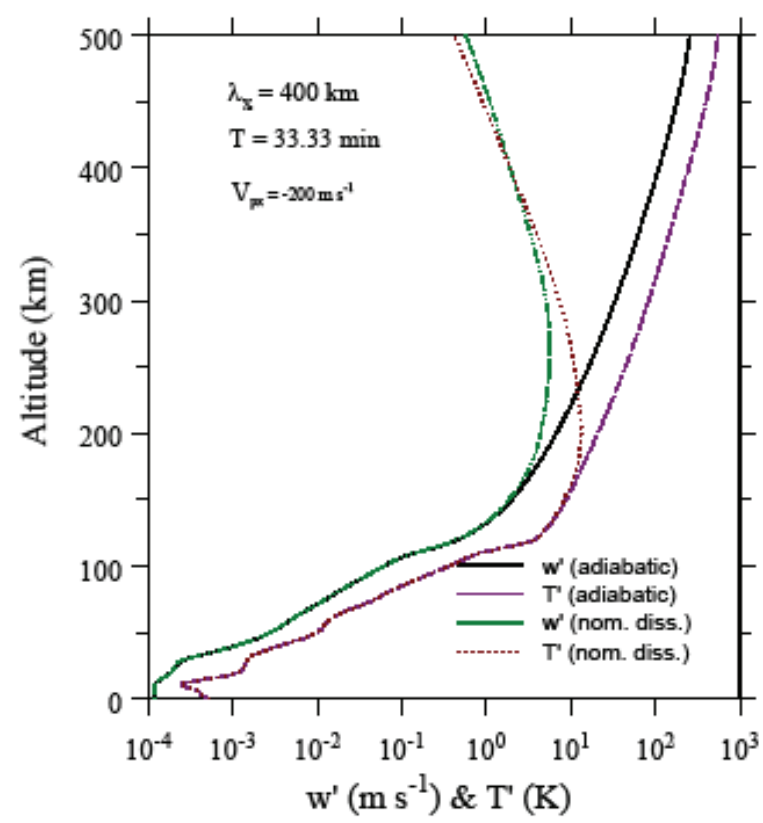

Fig. 3a. Vertical velocity and temperature perturbation amplitudes for adiabatic and nonadiabatic waves of $400 \mathrm{~km}$ horizontal wavelength and 33 min period (after Hickey et al., 2009)

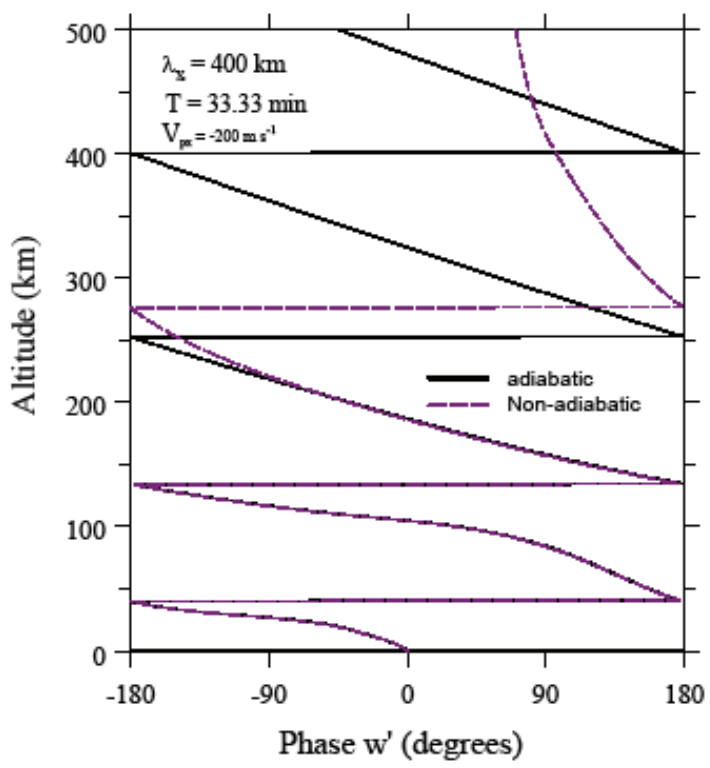

Fig. 3b. As in Figure 2a except for the phases (after Hickey et al., 2009) 


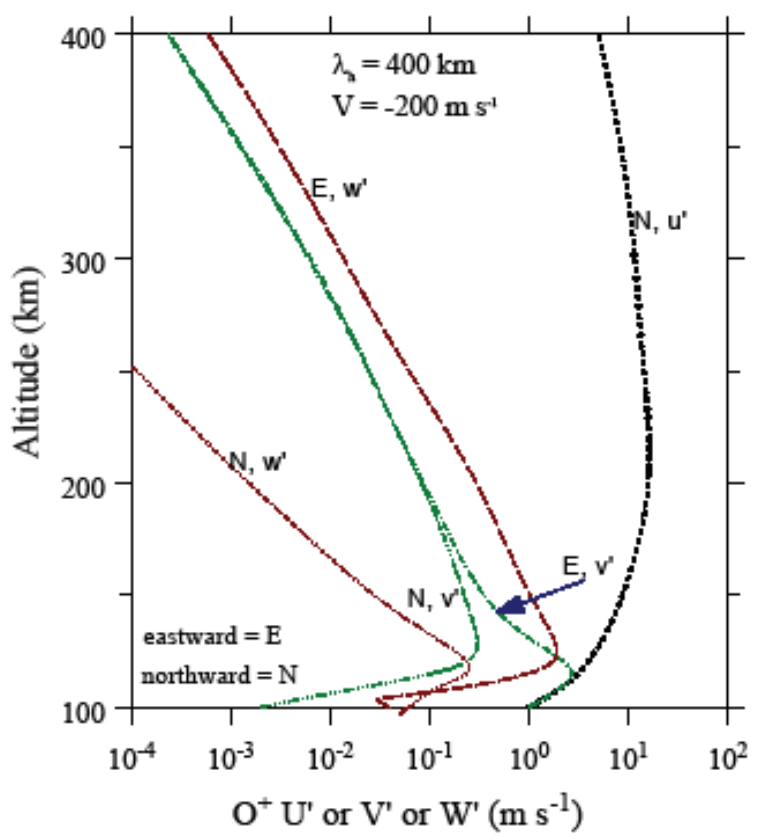

Fig. 4a. Ion velocity components for $\mathrm{O}^{+}$for northward and eastward propagating waves at the equator (after Hickey et al., 2010a)

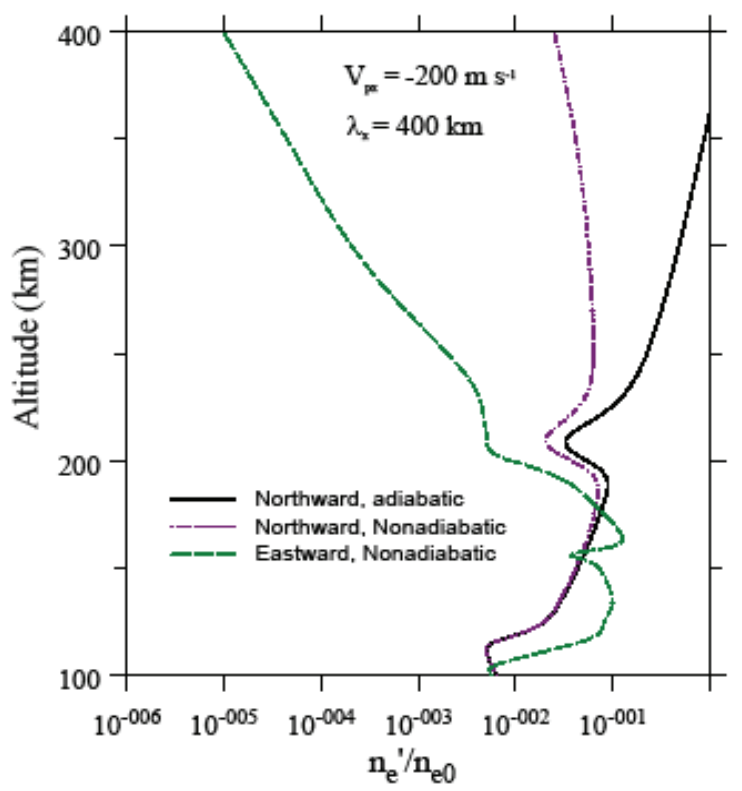

Fig. 4b. (after Hickey et al., 2009) 
for northward wave propagation and for the meridional perturbation velocity (of $\sim 15 \mathrm{~m} / \mathrm{s}$ at $200 \mathrm{~km}$ altitude). By comparison, the ion velocity response is small for an eastward propagating wave, and is largest for the vertical ion velocity $(\sim 0.2 \mathrm{~m} / \mathrm{s}$ at $200 \mathrm{~km}$ altitude). The associated electron density response is shown in Figure $4 \mathrm{~b}$. For realistic dissipation (nonadiabatic case) the largest response (of $\sim 7 \%$ of the mean at $300 \mathrm{~km}$ altitude) occurs for the northward propagating wave. With small dissipation and for the northward propagating wave the electron density response is about an order of magnitude larger than this.

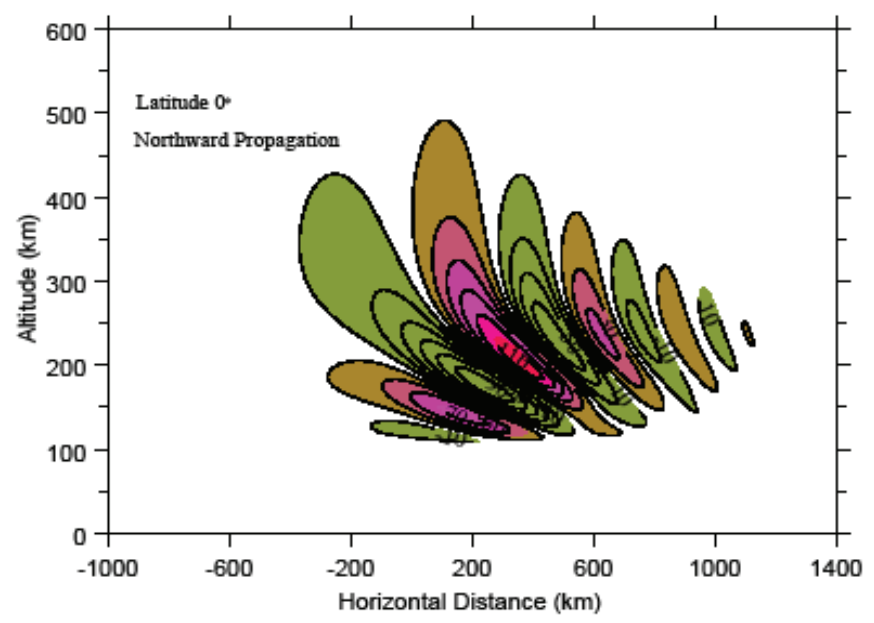

Fig. 5a. Temperature fluctuation (in K) for a northward propagating gravity wave disturbance (after Hickey et al., 2010a)

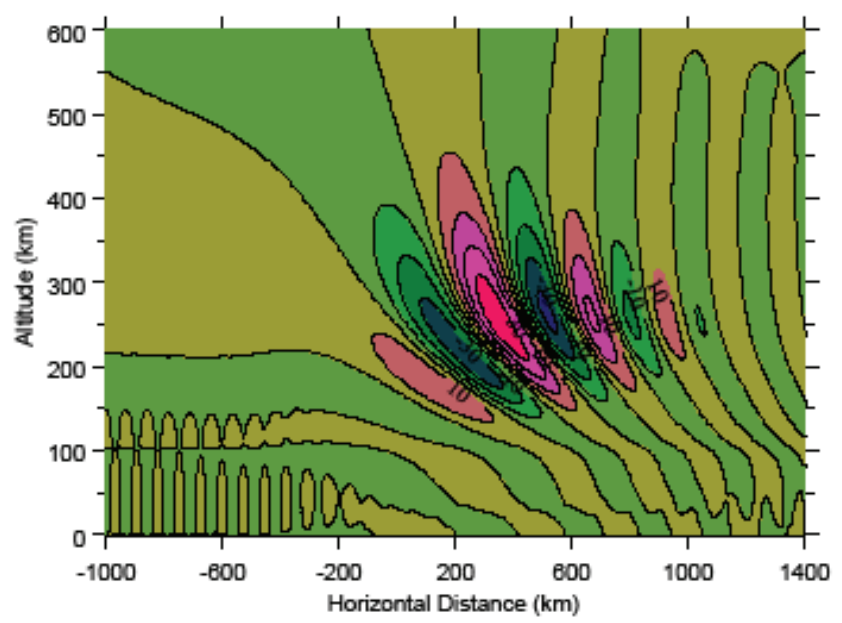

Fig. 5b. Vertical velocity fluctuation (in $\mathrm{m} / \mathrm{s}$ ) for a northward propagating gravity wave disturbance 


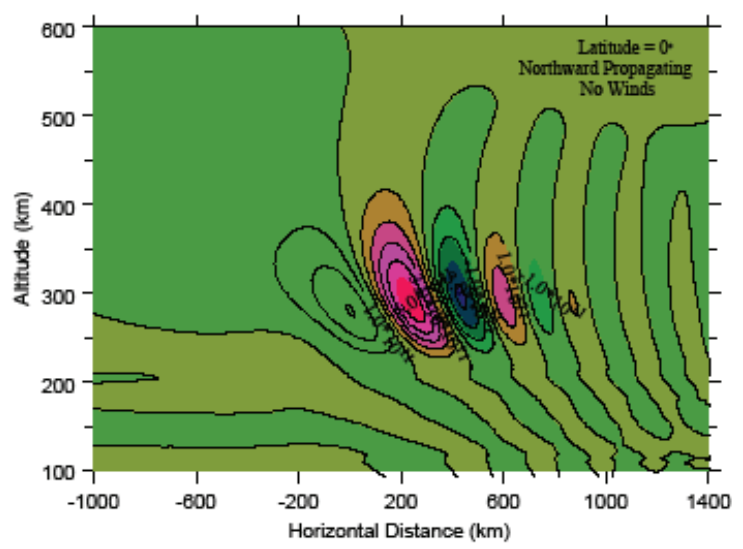

Fig. 6a. Electron density perturbations for northward propagation including dissipation and without mean winds (after Hickey et al., 2009)

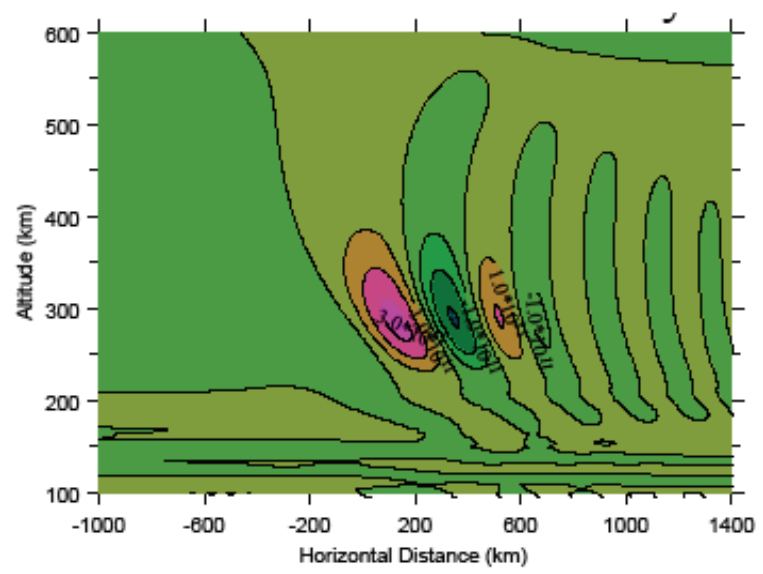

Fig. 6b. As in Figure 6a, except with the inclusion of mean winds (after Hickey et al., 2009)

The results of the spectral full-wave model are now discussed. Figure $5 \mathrm{a}$ shows the temperature fluctuation as a function of height and horizontal position for a northward propagating gravity wave disturbance with realistic dissipation included. The maximum perturbation of $\sim 130 \mathrm{~K}$ (which is about $20 \%$ of the mean, undisturbed temperature) occurs over the 200 to $250 \mathrm{~km}$ altitude region. At greater heights the phase fronts become more vertical as a consequence of the increasing dissipation due to viscosity and thermal conduction (Hines, 1968). Figure $5 \mathrm{~b}$ shows the corresponding vertical velocity fluctuation. The maximum of $\sim 30 \mathrm{~m} / \mathrm{s}$ occurs near $300 \mathrm{~km}$ altitude. About two to three dominant cycles are evident in these results.

Next we examine the effects of mean winds on the electron density response for a northward propagating gravity wave disturbance with realistic dissipation. Figure 6a shows the electron density response as a function of height and horizontal position without mean 
winds included. The maximum perturbations occur at the F2 peak near $300 \mathrm{~km}$ altitude and are localized to a horizontal region of $\sim 800 \mathrm{~km}$ extent (which is twice the dominant horizontal wavelength). The maximum perturbation is $\sim 60 \%$ of the mean at $\mathrm{x} \sim 200 \mathrm{~km}$. With the further inclusion of mean winds (Figure $6 \mathrm{~b}$ ) the maximum perturbation is $\sim 30 \%$ of the mean, while the horizontal extent of the disturbance has been reduced.

In order to simulate GPS observations, we have performed vertical integrations of the electron density perturbations to obtain the total electron content (TEC) perturbations. The integration of the mean, undisturbed electron density profile gives a TEC value of 17 TECU (where $1 \mathrm{TECU}=10^{16}$ electrons $/ \mathrm{m}^{2}$ ). For northward propagation (Figure $7 \mathrm{a}$ ), TEC fluctuations are largest for the quasi-adiabatic, windless case. The inclusion of dissipation reduces the TEC fluctuation amplitude and also alters the phase of the disturbance. The further inclusion of mean winds alters the phase again, and causes a further reduction in the amplitude of the perturbations. In this latter (and more realistic) case the maximum TEC perturbations are about 3 TECU, which corresponds to an approximate $20 \%$ perturbation about the mean.

The results for an eastward propagating wave disturbance are shown in Figure $7 \mathrm{~b}$. Immediately evident is the significantly smaller response than for the northward propagating disturbance. As before, the smallest response occurs when dissipation and mean winds are included, and the maximum amplitude is $\sim 0.01$ TECU. It should be noted that these results apply to the equator. At mid-latitudes the ionospheric response to a zonally propagating gravity wave disturbance will be much larger, and can be comparable to that obtained for a meridionally propagating gravity wave disturbance (Occhipinti et al., 2008). This is because the vertical velocity fluctuation has a component parallel to the geomagnetic field at mid-latitudes, which can thus impart ion motion in that direction.

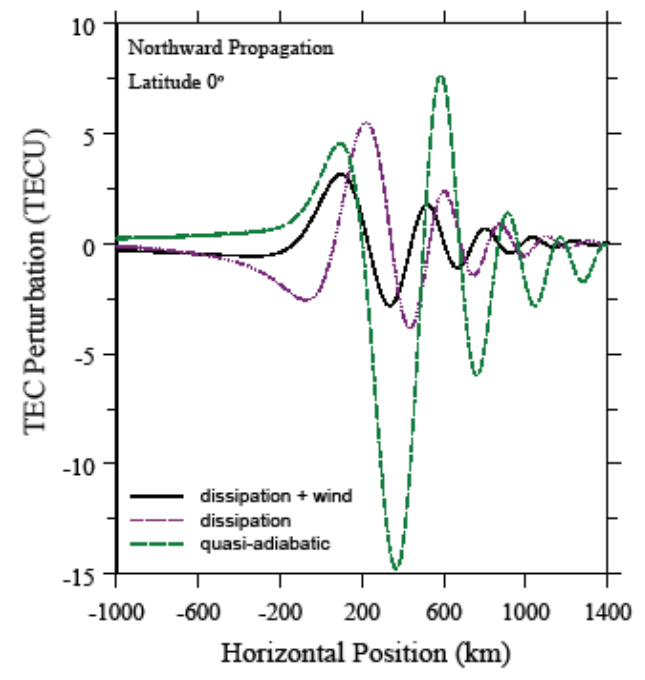

(a)

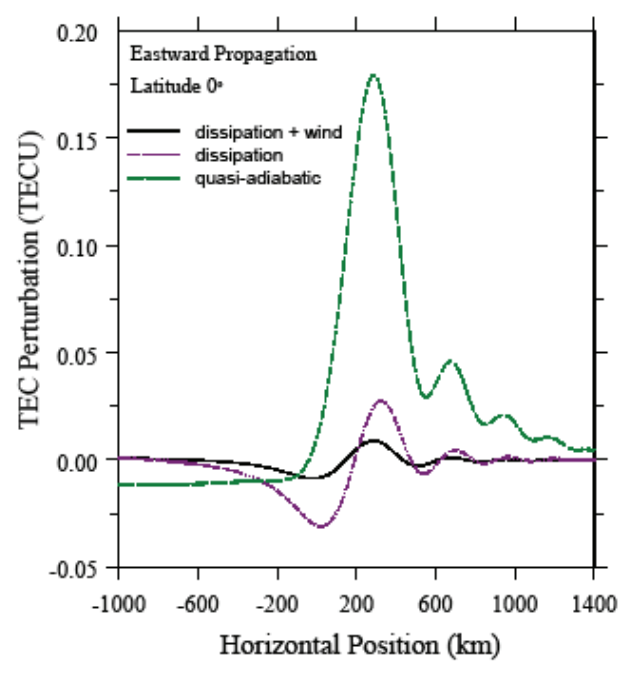

(b)

Fig. 7. (a) TEC fluctuations for northward propagation (after Hickey et al., 2009). (b) TEC fluctuations for eastward propagation (after Hickey et al., 2009). 


\subsection{Airglow fluctuations}

Atmospheric gravity waves propagating in the thermosphere are known to produce airglow variations associated with the wave-perturbed chemistry. Gravity wave motions have been detected in the 6300 A (red-line) nightglow (e.g., Sobral et al., 1978; Mendillo et al., 1997; Kubota et al., 2001), and also in the far-ultraviolet (FUV) O 1356 A emission (Paxton et al., 2003; DeMajistre et al., 2007). The chemistry associated with these emissions is included in Table 1 in Appendix 1. The mean undisturbed electron density profile is shown in Figure 8. Also shown are the altitude profiles of the mean undisturbed volume emission rates (VER) for these two emissions. The O $1356 \AA$ VER peaks near $300 \mathrm{~km}$ altitude with a value of $\sim 7.2$ $\mathrm{x} 10^{5}$ photons $/ \mathrm{s} / \mathrm{m}^{3}$, and the OI $6300 \AA$ VER peaks near $254 \mathrm{~km}$ altitude with a value of $\sim 8.6$ $x 10^{7}$ photons $/ \mathrm{s} / \mathrm{m}^{3}$. The former profile is broader in its altitude extent than the latter.

The resulting OI $6300 \AA$ VER perturbations for northward propagation at the equator, with nominal dissipation and in the absence of mean winds are shown as a function of height and horizontal position in Figure 9. For this particular gravity wave disturbance the perturbations maximize in the vicinity of the altitude where the mean undisturbed OI 6300 $\AA$ VER (shown in Figure 8) maximizes. The maximum value of the perturbation VER is $\sim 6 \mathrm{x}$ $10^{7}$ photons $/ \mathrm{s} / \mathrm{m}^{3}$, which is about $70 \%$ of the mean undisturbed value. Two complete cycles of the disturbance are evident in the VER fluctuations. Note that although we do not show the O $1356 \AA$ VER perturbations, they resemble those for the OI $6300 \AA$ except the maxima occur closer to $300 \mathrm{~km}$ altitude, in the vicinity of the peak undisturbed O $1356 \AA$ profile (see Hickey et al., 2010a).

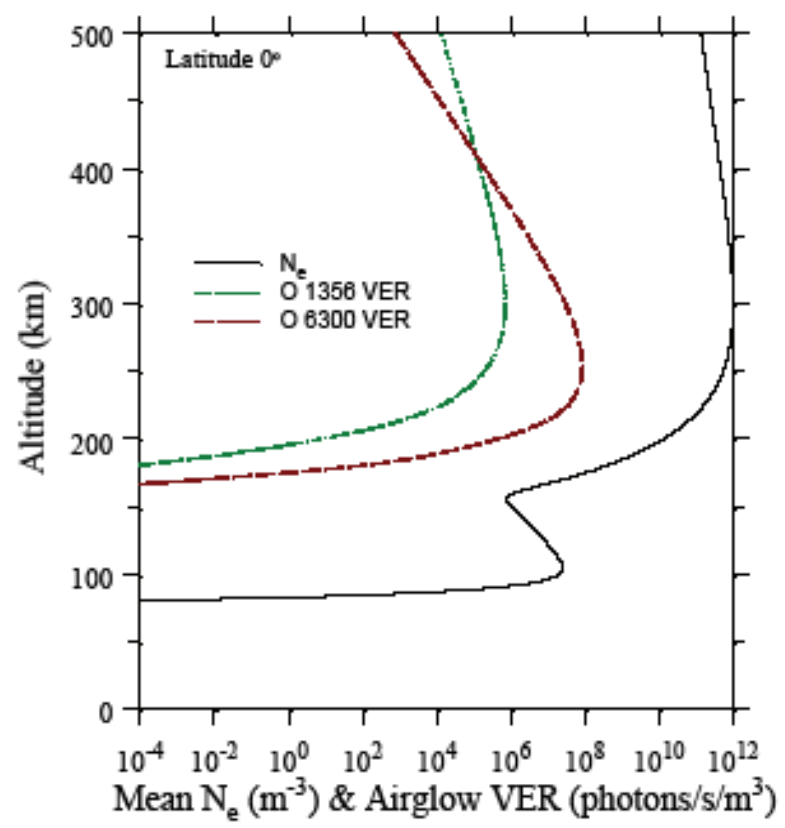

Fig. 8. Mean electron density $\left(\mathrm{m}^{-3}\right)$, mean OI $6300 \AA$ I VER (photons $/ \mathrm{s} / \mathrm{m}^{3}$ ), and mean O 1356 $\AA$ VER (photons $/ \mathrm{s} / \mathrm{m}^{3}$ ) (after Hickey et al., 2010a) 


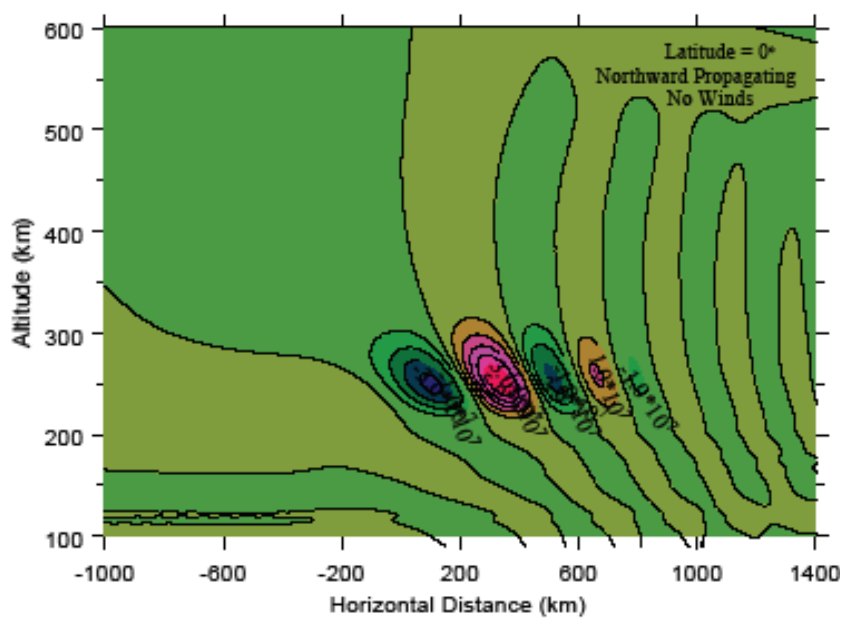

Fig. 9. OI $6300 \AA$ VER fluctuations as a function of altitude and horizontal position (after Hickey et al., 2010a)

The brightness fluctuations are now obtained by integration over altitude of the VER fluctuations. We have done so for both the OI $6300 \AA$ and the O $1356 \AA$ emissions. We have also performed two integrations, one vertically, and the other along an oblique slant path inclined at an angle of $\sim 29^{\circ}$ from the horizontal. In each case we have then normalized the brightness fluctuations to the mean undisturbed brightness to obtain the relative brightness fluctuations (see Figure 10). The maximum relative brightness fluctuations for the OI $6300 \AA$ emission (Figure 10a) are $\sim 50 \%$ for overhead viewing and $25 \%$ for oblique viewing. The maximum occurs almost $400 \mathrm{~km}$ earlier for the oblique viewing, which equates to a time difference of $\sim 30$ minutes. Hence, for oblique viewing the disturbance could be observed approximately 30 minutes earlier compared to overhead viewing.

Similar results are seen for the O $1356 \AA$ emission (Figure 10b). The relative brightness fluctuation is smaller for oblique viewing ( $18 \%$ versus $43 \%)$, but appears $\sim 400 \mathrm{~km}$ (corresponding to $\sim 30$ minutes) earlier than for overhead viewing. Also shown in this figure are the relative TEC fluctuations for overhead and oblique viewing. They strongly resemble the O $1356 \AA$ fluctuations in terms of amplitude and phase. For overhead viewing both waveforms look strikingly similar to the original lower boundary/tsunami disturbance shown in Figure 2a. The maximum relative TEC fluctuations are $\sim 33 \%$ and $8 \%$ for overhead and oblique viewing, respectively.

\subsection{Momentum transport}

Atmospheric gravity waves transport momentum and sensible heat. The respective fluxes per unit volume of these quantities are given by $F_{m}=\bar{\rho}\left\langle u^{\prime} w^{\prime}\right\rangle$ and $F_{s h}=\bar{\rho} c_{p}\left\langle w^{\prime} T^{\prime}\right\rangle$, where all symbols are as previously defined, and where the brackets denote an average over a complete horizontal wavelength of the wave disturbance. Here we will focus primarily on the momentum flux and its possible impact on the thermosphere. The impact of the sensible heat flux will be briefly summarized towards the end of this section. A more complete description of these wave fluxes associated with tsunamis is given by Hickey et al. (2010b). 


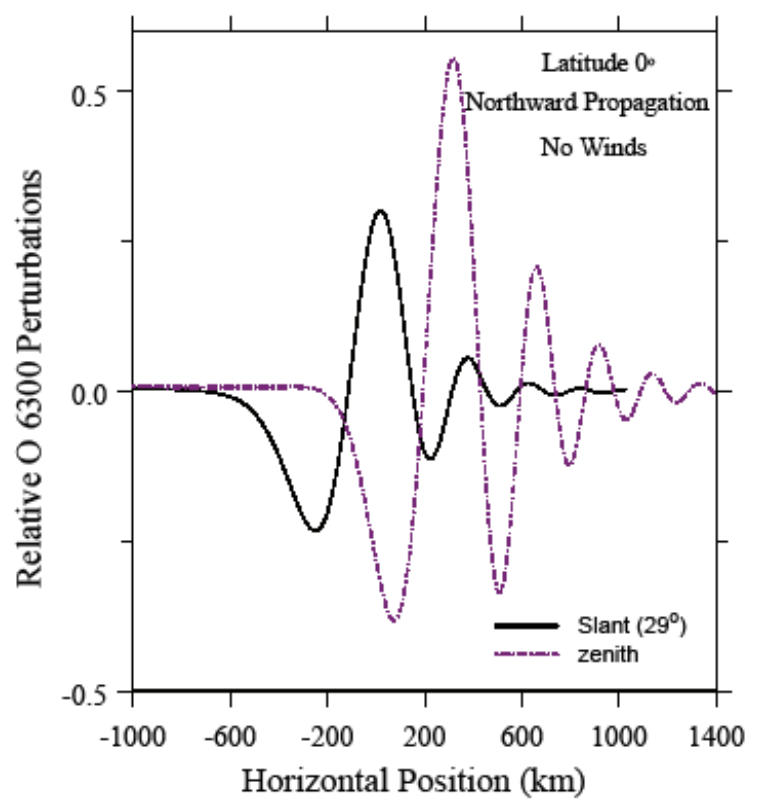

Fig. 10a. OI $6300 \AA$ A relative brightness fluctuations for overhead and oblique viewing (after Hickey et al., 2010a)

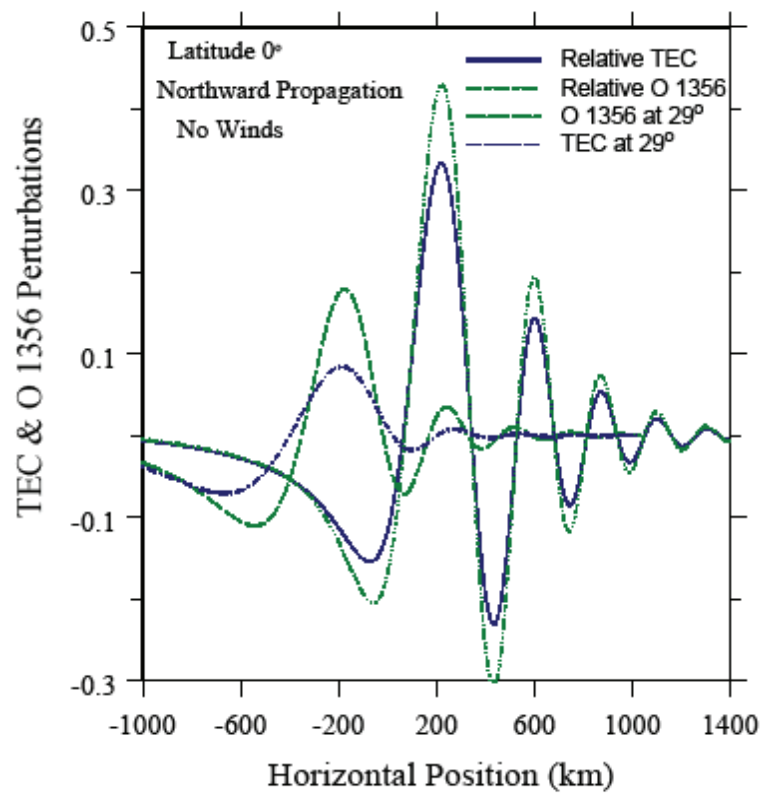

Fig. 10b. Relative total electron content and O 1356 A fluctuations for overhead and oblique viewing (after Hickey et al., 2010a) 
The non-acceleration conditions are that the waves be steady, linear, non-dissipating, and do not encounter critical levels (Walterscheid, 1995). For waves that satisfy the non-acceleration conditions the wave fluxes remain constant as the waves propagate upward. If these conditions are violated, the wave fluxes will change with height and the atmosphere can be irreversibly altered (eventually relaxing to a new steady-state). In particular, waves propagating into the thermosphere will eventually be viscously damped and a convergence of the momentum flux will occur, with a concomitant acceleration of the mean state given by

$$
\frac{\partial \bar{u}_{2}}{\partial t}=-\frac{1}{\bar{\rho}} \frac{d}{d z}\left(\bar{\rho}\left\langle u^{\prime} w^{\prime}\right\rangle\right)
$$

Here $\bar{u}_{2}$ is the second order, horizontally averaged change in mean state velocity associated with gravity wave forcing. This forcing is important in the terrestrial mesosphere, but in this case it is the wave amplitudes becoming nonlinear with subsequent wave breaking that leads to a momentum flux convergence. Fast gravity waves, such as those associated with tsunamis, should experience a large amplitude growth as they propagate upward through the thermosphere because they have large vertical wavelengths and so are far less dissipated than slower waves. Because they can attain large amplitudes in the middle thermosphere, their eventual dissipation might lead to large values of $\bar{u}_{2}$.

The major part of the gravity wave disturbance shown previously in Figure (5a) lies in a horizontal region of approximately $800 \mathrm{~km}$ extent. We calculate horizontal averages of wave fluxes over this horizontal extent in order to determine the second-order forcing of the atmosphere. Specifically, for a physical quantity $\psi^{\prime}$, we calculate the horizontally averaged vertical flux by evaluating

$$
\left\langle w^{\prime} \psi^{\prime}\right\rangle=\frac{1}{N} \sum_{j=1}^{N} \operatorname{Re}\left(w_{j}^{\prime}\right) \operatorname{Re}\left(\psi_{j}^{\prime}\right)
$$

In Equation (13), $j$ is an index denoting the horizontal position of the physical variables $w_{j}^{\prime}$ and $\psi_{j}^{\prime}$ calculated from an inverse discrete Fourier transform over all waves in the spectrum. Also, $N$ is the number of points at which the variables are evaluated over the 800 $\mathrm{km}$ horizontal extent of the disturbance.

The disturbance momentum flux per unit mass $\left(\left\langle u^{\prime} w^{\prime}\right\rangle\right)$ is shown in Figure 11a. At all altitudes shown it is negative and in the same direction as the phase propagation. Its magnitude increases with increasing height in the thermosphere, achieving a maximum value of $\sim 1800 \mathrm{~m}^{2} \mathrm{~s}^{-2}$ near $230 \mathrm{~km}$ altitude, and decreasing at greater heights due to viscous dissipation. The associated mean state acceleration is shown in Figure 11b. It maximizes in the middle thermosphere (near $250 \mathrm{~km}$ altitude) with a value of $\sim 230 \mathrm{~m} \mathrm{~s}^{-1} \mathrm{~h}^{-1}$ (in the same direction as the phase velocity) and with a full-width at half maximum of $\sim 120 \mathrm{~km}$. Hence the dissipating disturbance drives a deep region of the thermosphere. Because the dominant part of the disturbance is of $\sim 800 \mathrm{~km}$ horizontal extent (which is twice the dominant horizontal wavelength in the spectrum), the forcing would occur for $\sim 1 \mathrm{~h}$ (two wave periods). Hence the acceleration shown in Figure $11 \mathrm{~b}$ can be interpreted as the estimated change in velocity of this region of the thermosphere. This forcing would be applied over a large area ( $8000 \mathrm{~km}$ along-track for $10 \mathrm{~h}$ of propagation, and over a broad lateral extent). The 
viscous relaxation time was estimated by Hickey et al. (2010b) to be $\sim 10 \mathrm{~h}$ near $200 \mathrm{~km}$ altitude and a few tens of minutes near $300 \mathrm{~km}$ altitude. Hence the high altitude $(>250 \mathrm{~km})$ acceleration shown in Figure $11 \mathrm{~b}$ is probably an overestimate. Note that because the wave forcing is second order, it is proportional to the square of the wave amplitude. Hence, only the largest amplitude tsunamis may be able to produce such large mean state forcing of the thermosphere.

The sensible heat flux has been previously discussed in the literature (Walterscheid, 1981, 1995) and was calculated by Hickey et al. (2010b) for the tsunamigenic disturbance related to the Sumatra 2004 event. In this case the atmospheric heating and cooling due to the dissipating disturbance (not shown) was found to be $\sim+25 \mathrm{~K} \mathrm{~h}^{-1}$ near $180 \mathrm{~km}$ altitude, and $-25 \mathrm{~K} \mathrm{~h}^{-1}$ near $290 \mathrm{~km}$ altitude. The expected temperature changes are relatively small compared to the undisturbed mean state temperature $(\sim 753 \mathrm{~K})$ and may be too small to be unambiguously identified in observations.

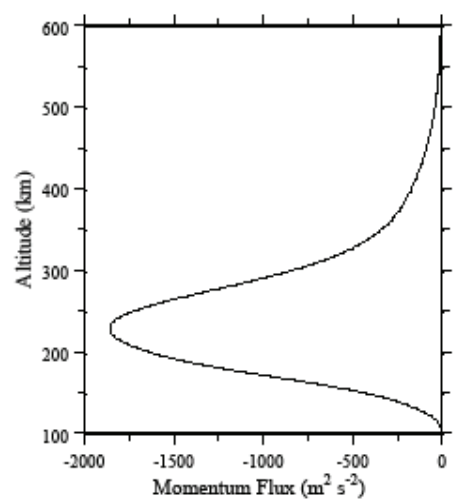

Fig. 11a. Disturbance momentum flux $\left(\mathrm{m}^{2} \mathrm{~s}^{-2}\right)$ (after Hickey et al., 2010b)

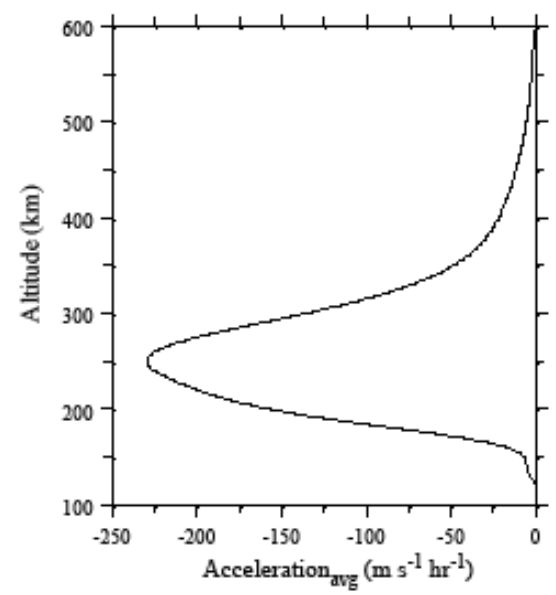

Fig. 11b. Horizontally averaged mean state acceleration due to the divergence of the disturbance momentum flux (after Hickey et al., 2010b) 


\section{Discussion}

We have used a linear model to describe the gravity wave disturbance. For the motions of the neutral atmosphere considered here this is a reasonable assumption. Orlanski and Bryan (1969) showed that a criterion for the onset of convective instability is $u^{\prime}>c$, where $u^{\prime}$ is the horizontal velocity perturbation and $c$ is the horizontal phase speed of the wave. We find that the maximum value of $u^{\prime}$ is $\sim 100 \mathrm{~m} / \mathrm{s}$, while $c$ is $200 \mathrm{~m} / \mathrm{s}$. However, the ionospheric perturbations we have obtained are quite large, up to $\sim 60 \%$ of the mean for realistic dissipation included, for which the assumption of linearity is violated. Nonetheless, we expect the results obtained to provide an overall good description of the expected ionospheric response. Future work should include a nonlinear treatment of this aspect of the model.

The work described herein was based on an assumed shallow water phase speed of $200 \mathrm{~m} / \mathrm{s}$ and an ocean depth of $\sim 4 \mathrm{~km}$. Further numerical experimentation (not shown) has investigated the effect of changing this phase speed. Decreasing the phase speed results in a decrease in the vertical wavelength of the gravity waves in the spectrum. This leads to an increase in the viscous dissipation rate of the waves in the thermosphere. Because of this, these waves do not penetrate as far into the thermosphere as the faster waves do, and so achieve smaller amplitudes. Increasing the phase speed brings the waves closer to evanescence over much of the mesosphere (see discussion in Hickey et al., 2009), and so somewhat impedes their propagation to greater altitudes. Hence, we find that $200 \mathrm{~m} / \mathrm{s}$ is close to an optimum phase speed for efficient gravity wave propagation from the lower atmosphere to the thermosphere. This in turn implies that the ionospheric response to tsunamis should maximize in regions where the ocean depth is $\sim 4 \mathrm{~km}$.

\section{Conclusions}

Tsunamis are a relatively rare event, but nonetheless in some instances they may have large, dramatic effects on the upper atmosphere. In addition to causing large fluctuations in electron density and in the total electron content, they will also cause comparable fluctuations in natural airglow emissions, such as the OI $6300 \mathrm{~A}$ and $\mathrm{O} 1356 \mathrm{~A}$ emissions. These airglow emissions could be observed from the ground and from space, and could help provide additional information leading to the early detection of tsunamis. The disturbances may, at times, carry significant wave momentum to F-region altitudes leading to strong accelerations of the mean flow. The observations of such events may offer an excellent opportunity of testing gravity wave theories and models, and we suggest that dedicated observations should be considered for future programs to study lower-upper atmosphere coupling and to better understand the role of tsunamis in this process.

\section{Acknowledgements}

This work was supported by NSF grant ATM-0639293 to Embry-Riddle Aeronautical University. The author appreciates conversations with colleagues Drs. Richard Walterscheid, Gerald Schubert, Attila Komjathy, David Galvin, and Tony Mannucchi over the course of this research.

\section{References}

Abe, K. (2006). Dominant periods of the 2004 Sumatra tsunami and the estimated source size, Earth Planets Space, 58, 217-221. 
Artru, J., V. Ducic, H. Kanamori, P. Lognonne, and M. Murakami (2005a). Ionospheric detection of gravity waves induced by tsunamis, Geophys. J. Int., 160, 840-848.

Artru, J., P. Lognonne, G. Occhipinti, F. Crespon, R. Garcia, E. Jeansou, and M. Murakami (2005b). Tsunami detection in the ionosphere, Space Res. Today, 163, 23-27.

Bruce, G. H., D. W. Peaceman, H. H. Rachford, Jr., and J. D. Rice (1953). Calculations of unsteady-state gas flow through porous media, Petrol. Trans. AIME, 198, 79-92.

DasGupta, A., Das., A., Hui, D., Bandyopadhyay, K. K., and Sivaraman, M. R. (2006). Ionospheric perturbation observed by the GPS following the December 26 th 2004 Sumatra-Andaman earthquake, Earth Planets Space, 35, 929-959.

DeMajistre, R., Paxton, L. J., and Bilitza, D. (2007). Comparison of ionospheric measurements made by digisondes with those inferred from ultraviolet airglow, Adv. Space Res., 39, 918-925.

Fritts, D. C., and Alexander, M. J. (2003). Gravity wave dynamics and effects in the middle atmosphere, Rev. Geophys., 41(1), 1003, doi:10.1029/2001RG000106.

Georges, T. M. (1968). HF Doppler studies of traveling ionospheric disturbances, J. Atmos. Terr. Phys., 30, 735-746.

Hébert, H., Sladen, A., and Schindelé, F. (2007). Numerical modeling of the great 2004 Indian Ocean tsunami: Focus on the Mascarene Islands. Bull. Seismol. Soc. Am., 97, 1A, S208S222.

Hedin, A. E. (1991). Extension of the MSIS thermosphere model into the middle and lower atmosphere, J. Geophys. Res., 96, 1159.

Hedin, A. E., et al. (1996). Empirical wind model for the upper, middle and lower atmosphere, J. Atmos. Terr. Phys., 58, 1421.

Hickey, M. P. and Cole, K. D. (1987). A Quartic Dispersion Equation for Internal Gravity waves in the Thermosphere. J. Atmos. Terr. Phys., 49, 889.

Hickey, M. P., Walterscheid, R. L. and Schubert, G. (2004). Erratum to “Gravity Wave Heating and Cooling in Jupiter's Thermosphere", Icarus, 170, 524-525.

Hickey, M. P., Walterscheid, R. L., Taylor, M. J., Ward, W., Schubert, G., Zhou, Q., Garcia, F., Kelley, M. C., and Shepherd, G. G. (1997). Numerical Simulations of Gravity Waves Imaged over Arecibo during the 10-day January 1993 Campaign, J. Geophys. Res., 102, 11,475 .

Hickey, M. P., Schubert, G., and Walterscheid, R. L. (2009). The Propagation of TsunamiDriven Gravity Waves into the Thermosphere and Ionosphere, J. Geophys. Res., 114, A08304, doi:10.1029/2009JA014105.

Hickey, M. P., Schubert, G., and Walterscheid, R. L. (2010a). Atmospheric airglow fluctuations due to a tsunami-driven gravity wave disturbance, J. Geophys. Res., 115, A06308, doi:10.1029/2009JA014977.

Hickey, M. P., Walterscheid, R. L. and Schubert, G. (2010b). Wave mean flow interactions in the thermosphere induced by a major tsunami, J. Geophys. Res., 115, A09309, doi:10.1029/2009JA014927.

Hines, C. O. (1960). Internal atmospheric gravity waves at ionospheric heights, Can. J. Phys., 38, 1441.

Hines, C. O. (1972). Gravity waves in the atmosphere, Nature, 239, 73-78.

Hines, C. O. (1968). An effect of molecular dissipation in upper atmospheric gravity waves, J. Atmos. Terr. Phys., 30, 845-849.

Hooke, W. H. (1968). Ionospheric irregularities produced by internal atmospheric gravity waves. J. Atmos. Sol. Terr. Phys., 30, 795-823.

Kelley, M. C. (1989). The Earth's Ionosphere, Academic Press Inc. 
Kubota, M., Kukunishi, H., and Okano, S. (2001). Characteristics of medium- and large-scale TIDs over Japan derived from OI 630-nm nightglow observations, Earth Planets Space, 53, 741-751.

Lee, M. C., Pradipta, R., Burke, W. J., Labno, A., Burton, L. M., Cohen, J. A., Dorfman, S. E., Coster, A. J., Sulzer, M. P., and Kuo, S. P. (2008). Did tsunami-launched gravity waves trigger ionospheric turbulence over Arecibo? J. Geophys. Res., 113, A01302, doi:10.1029/2007JA012615.

Lighthill, J. (1978). Waves in Fluids, Cambridge University Press, Cambridge.

Lindzen, R. S., and H. L. Kuo (1969). A reliable method for the numerical integration of a large class of ordinary and partial differential equations. Mon. Wea. Rev., 97, 732-734.

Liu, J., Tsai, Y., Chen, S., Lee, C., Chen, Y., Yen, H., Chang, W., and Liu, C. (2006a). Giant ionospheric disturbances excited by the M9.3 Sumatra earthquake of 26 December 2004. Geophys. Res. Lett., 33, L021103, doi:10.1029/2005GL023963.

Liu, J., Tsai, Y., Ma, K., Chen, Y., Tsai, H., Lin, C., Kamogawa, M., and Lee, C. (2006b). Ionospheric GPS total electron content (TEC) disturbances triggered by the 26 December 2004 Indian Ocean tsunami, J. Geophys. Res., 111, A05303, doi:10.1029/2005JA011200.

Martyn, D. F. (1950). Cellular atmospheric waves in the ionosphere and troposphere, Proc. Roy. Soc., A201, 216.

McLeod, M. A. (1965). Sporadic E Theory. I. Collision-Geomagnetic Equilibrium, J. Atmos. Sci., 23, 96-109.

Mendillo, M., Baumgardner, J., Nottingham, D., Aarons, J., Reinisch, B., Scali, J., and Kelley, M. C. (1997). Investigations of thermospheric-ionospheric dynamics with 6300- $\AA$ images from the Arecibo Observatory, J. Geophys. Res., 102, 7331-7343.

Munro, G. H. (1948). Short period changes in the F-region of the ionosphere, Nature, 162, 886.

Occhipinti, G., P. Lognonne, E. A. Kherani, and H. Hebert (2006). Three-dimensional waveform modeling of ionospheric signature induced by the 2004 Sumatra tsunami, Geophys. Res. Lett., 33, L20104, doi::10.1029/2006GL026865.

Occhipinti, G., E., A. Kherani, and P. Lognonne (2008). Geomagnetic dependence of ionospheric disturbances induced by tsunamigenic internal gravity waves, Geophys. J. Int., 173, 753-765.

Orlanski, I., and Bryan, K. (1969). Formation of the thermocline step structure by largeamplitude internal gravity waves, J. Geophys. Res., 74, 6975-6983.

Parish, H. F., Schubert, G., Hickey, M. P., and Walterscheid, R. L. (2009). Propagation of tropospheric gravity waves into the upper atmosphere of Mars, Icarus, doi:10.1016/j.icarus.2009.04.031.

Paxton, L. J., Morrison, D., Strickland, D. J., McHarg, M. J., Zhang, Y., Wolven, B., Kil, H., Crowley, G., Christensen, A. B., and Meng, C.-I. (2003). The use of far ultraviolet remote sensing to monitor space weather, Adv. Space Res., 31(4), 813-818.

Peltier, W. R., and Hines, C. O. (1976). On the possible detection of tsunamis by a monitoring of the ionosphere, J. Geophys. Res., 81, 1995-2000.

Schubert, G., Hickey, M. P., and Walterscheid, R. L. (2003). Heating of Jupiter's thermosphere by the dissipation of upward propagating acoustic waves, Icarus., 163, 398-413.

Schubert, G., M. P. Hickey, and R. L. Walterscheid (2005). Physical processes in acoustic wave heating of the thermosphere, J. Geophys. Res., 110, D07106, doi:10.1029/2004JD005488.

Schunk, R. and J. Sojka (1996). USU model of the global ionosphere, in STEP: Handb. of Ionospheric Models, Ed. R.W. Schunk, SCOSTEP.

Scorer, R. S. (1949). Theory of waves in the lee of mountains, Q. J. Roy. Met. Soc., 75, 323, 41-56. 
Walterscheid, R. L., G. Schubert, and J. Straus (1987). A dynamical-chemical model of wavedriven fluctuations in the $\mathrm{OH}$ nightglow, J. Geophys. Res., 92, 1241-1254.

Walterscheid, R. L., and M. P. Hickey (2001). One-gas models with height-dependent mean molecular weight: Effects on gravity wave propagation, J. Geophys. Res., 106, 28,83128,839 .

Wilson, M. (2005). Modeling the Sumatra-Andaman earthquake reveals a complex, nonuniform rupture, Phys. Today, 58, 19.

\section{Appendix 1.}

\begin{tabular}{|c|c|c|}
\hline & Ion Reaction & Rate $\left(\mathrm{cm}^{3} \mathrm{~s}^{-1}\right)$ \\
\hline 1 & $\mathrm{O}^{+}+\mathrm{N}_{2} \rightarrow \mathrm{NO}^{+}+\mathrm{N}$ & $k_{1}=5 \times 10^{-13}$ \\
\hline 2 & $\mathrm{O}^{+}+\mathrm{O}_{2} \rightarrow \mathrm{O}_{2}^{+}+\mathrm{O}$ & $k_{2}=2 \times 10^{-11}(\mathrm{~T} / 300)^{-0.4}$ \\
\hline 3 & $\mathrm{O}^{+}+\mathrm{NO} \rightarrow \mathrm{NO}^{+}+\mathrm{O}$ & $k_{3}=8 \times 10^{-13}$ \\
\hline 4 & $\mathrm{O}^{+}+\mathrm{e} \rightarrow \mathrm{O}(5 \mathrm{P})+\hbar v_{1356}$ & $k_{4}=7.3 \times 10^{-13}$ \\
\hline 5 & $\mathrm{O}_{2}^{+}+\mathrm{N}_{2} \rightarrow \mathrm{NO}^{+}+\mathrm{NO}$ & $k_{5}=5 \times 10^{-16}$ \\
\hline 6 & $\mathrm{O}_{2}^{+}+\mathrm{NO} \rightarrow \mathrm{NO}^{+}+\mathrm{O}_{2}$ & $k_{6}=4.4 \times 10^{-10}$ \\
\hline $7 a$ & $\mathrm{O}_{2}^{+}+\mathrm{e} \rightarrow \mathrm{O}+\mathrm{O}\left({ }^{3} \mathrm{P}\right)$ & $k_{7 \mathrm{a}}=0.62 \times 1.6 \times 10^{-7}(300 / \mathrm{T})^{0.55}$ \\
\hline $7 b$ & $\mathrm{O}_{2}{ }^{+}+\mathrm{e} \rightarrow \mathrm{O}+\mathrm{O}\left({ }^{1} \mathrm{~S}\right)$ & $k_{7 \mathrm{~b}}=0.08 \times 1.6 \times 10^{-7}(300 / \mathrm{T})^{0.55}$ \\
\hline $7 \mathrm{c}$ & $\mathrm{O}_{2}^{+}+\mathrm{e} \rightarrow \mathrm{O}+\mathrm{O}\left({ }^{1} \mathrm{D}\right)$ & $k_{7 \mathrm{c}}=1.30 \times 1.6 \times 10^{-7}(300 / \mathrm{T})^{0.55}$ \\
\hline 8 & $\mathrm{~N}_{2}^{+}+\mathrm{O} \rightarrow \mathrm{NO}^{+}+\mathrm{N}$ & $k_{8}=1.4 \times 10^{-10}(300 / \mathrm{T})^{0.44}$ \\
\hline 9 & $\mathrm{~N}_{2}^{+}+\mathrm{O} \rightarrow \mathrm{O}^{+}+\mathrm{N}_{2}$ & $k_{9}=1 \times 10^{-11}(300 / \mathrm{T})^{0.23}$ \\
\hline 10 & $\mathrm{~N}_{2}^{+}+\mathrm{O}_{2} \rightarrow \mathrm{O}_{2}^{+}+\mathrm{N}_{2}$ & $k_{10}=5 \times 10^{-11}(300 / \mathrm{T})^{-1}$ \\
\hline 11 & $\mathrm{~N}_{2}{ }^{+}+\mathrm{NO} \rightarrow \mathrm{NO}^{+}+\mathrm{N}_{2}$ & $k_{11}=3.3 \times 10^{-10}$ \\
\hline 12 & $\mathrm{~N}_{2}^{+}+\mathrm{e} \rightarrow \mathrm{N}+\mathrm{N}$ & $k_{12}=1.8 \times 10^{-7}(300 / \mathrm{T})^{0.39}$ \\
\hline 13 & $\mathrm{NO}^{+}+\mathrm{e} \rightarrow \mathrm{N}+\mathrm{O}$ & $k_{13}=4.2 \times 10^{-7}(300 / \mathrm{T})^{0.85}$ \\
\hline 14 & $\mathrm{O}\left({ }^{1 S}\right) \rightarrow \mathrm{O}\left({ }^{1} \mathrm{D}\right)+\hbar v_{5577}$ & $A_{5577}=1.06 \mathrm{~s}^{-1}$ \\
\hline $15 \mathrm{a}$ & $\mathrm{O}\left({ }^{1} \mathrm{D}\right) \rightarrow \mathrm{O}\left({ }^{3} \mathrm{P}\right)+\hbar v$ & $A_{6300+6364}=9.34 \times 10^{-3} \mathrm{~s}^{-1}$ \\
\hline $15 b$ & $\mathrm{O}\left({ }^{1} \mathrm{D}\right) \rightarrow \mathrm{O}\left({ }^{3} \mathrm{P}\right)+\hbar v_{6300}$ & $A_{6300}=7.1 \times 10^{-3} \mathrm{~s}^{-1}$ \\
\hline 16 & $\mathrm{O}\left({ }^{1} \mathrm{D}\right)+\mathrm{N}_{2} \rightarrow \mathrm{O}+\mathrm{N}_{2}$ & $k_{16}=2.0 \times 10^{-11} \exp [107.8 / \mathrm{T}]$ \\
\hline 17 & $\mathrm{O}\left({ }^{1} \mathrm{D}\right)+\mathrm{O}_{2} \rightarrow \mathrm{O}+\mathrm{O}_{2}$ & $k_{17}=2.0 \times 10^{-11} \exp [67.5 / \mathrm{T}]$ \\
\hline 18 & $\mathrm{O}\left({ }^{1} \mathrm{D}\right)+\mathrm{O} \rightarrow \mathrm{O}+\mathrm{O}$ & $k_{18}=8.0 \times 10^{-12}$ \\
\hline
\end{tabular}

Table 1. Chemical reactions for ions (after Hickey et al., 2010a) 


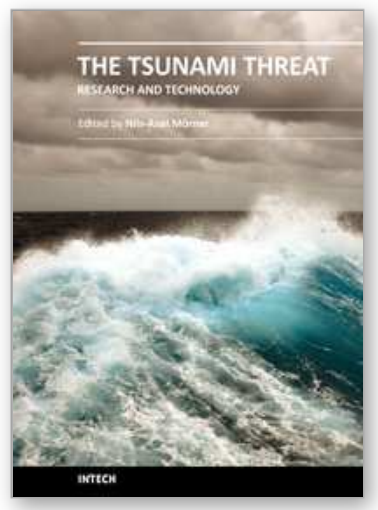

\author{
The Tsunami Threat - Research and Technology \\ Edited by Nils-Axel MÃ
}

ISBN 978-953-307-552-5

Hard cover, 714 pages

Publisher InTech

Published online 29, January, 2011

Published in print edition January, 2011

Submarine earthquakes, submarine slides and impacts may set large water volumes in motion characterized by very long wavelengths and a very high speed of lateral displacement, when reaching shallower water the wave breaks in over land - often with disastrous effects. This natural phenomenon is known as a tsunami event. By December 26, 2004, an event in the Indian Ocean, this word suddenly became known to the public. The effects were indeed disastrous and 227,898 people were killed. Tsunami events are a natural part of the Earth's geophysical system. There have been numerous events in the past and they will continue to be a threat to humanity; even more so today, when the coastal zone is occupied by so much more human activity and many more people. Therefore, tsunamis pose a very serious threat to humanity. The only way for us to face this threat is by increased knowledge so that we can meet future events by efficient warning systems and aid organizations. This book offers extensive and new information on tsunamis; their origin, history, effects, monitoring, hazards assessment and proposed handling with respect to precaution. Only through knowledge do we know how to behave in a wise manner. This book should be a well of tsunami knowledge for a long time, we hope.

\title{
How to reference
}

In order to correctly reference this scholarly work, feel free to copy and paste the following:

Michael P. Hickey (2011). Atmospheric Gravity Waves and Effects in the Upper Atmosphere Associated with Tsunamis, The Tsunami Threat - Research and Technology, Nils-Axel MÃ $\Uparrow$ rner (Ed.), ISBN: 978-953-307552-5, InTech, Available from: http://www.intechopen.com/books/the-tsunami-threat-research-andtechnology/atmospheric-gravity-waves-and-effects-in-the-upper-atmosphere-associated-with-tsunamis

\section{INTECH}

open science | open minds

\section{InTech Europe}

University Campus STeP Ri

Slavka Krautzeka 83/A

51000 Rijeka, Croatia

Phone: +385 (51) 770447

Fax: +385 (51) 686166

www.intechopen.com

\section{InTech China}

Unit 405, Office Block, Hotel Equatorial Shanghai

No.65, Yan An Road (West), Shanghai, 200040, China

中国上海市延安西路65号上海国际贵都大饭店办公楼405单元

Phone: +86-21-62489820

Fax: $+86-21-62489821$ 
(C) 2011 The Author(s). Licensee IntechOpen. This chapter is distributed under the terms of the Creative Commons Attribution-NonCommercialShareAlike-3.0 License, which permits use, distribution and reproduction for non-commercial purposes, provided the original is properly cited and derivative works building on this content are distributed under the same license. 